Uncertain trajectories in old age and implications for families and for palliative and end of life care policy and practice

\title{
Kathryn Almack
}

University of Hertfordshire

Address for correspondence:

Centre for Research in Public Health and Community Care (CRIPACC)

3F417 Health Research Building

School of Health and Social Work

University of Hertfordshire

College Lane | Hatfield | AL10 9AB

Tel: +44 1707281200

Email:k.almack@herts.ac.uk

Keywords: End-of-life care; death; families; ageing populations; elderly; palliative care; autoethnography

Acknowledgments: Thank you to my family members, friends, colleagues and reviewers who have contributed to the various drafts of this paper. In memory of my father, Leonard Douglas (Doug) Almack 28-02-22 to 11-09-11.

NB: Until in print (or early online edition available) in the Journal Death Studies, please do not cite without author's permission 


\section{Introduction}

The provision of high-quality care at the end-of-life, providing greater choice, and fulfilling people's preferences related to place of care and death is high on national (and international) agendas (Higginson, Sarmento, Calanzani, Benalia, \& Gomes, 2013). However, the greatest areas of unmet need are likely to be for those with a non-cancer diagnosis and among older people (Lloyd et al., 2016; Murray \& Moine, 2015). This paper draws on an autoethnographic account of the dying and death of my father (aged 89) to interrogate disjunctions between policy perspectives about end-of-life care and common experiences of elderly people who die in a hospital setting. Place of death varies considerably with age, with the oldest age groups most likely to die in hospital and people aged over 75 have the highest hospital death rates (National End of Life Care Intelligence Network, 2010).

In England, there has been an increased focus on end-of-life care and policy developments over the past decade, including the first English End of Life Care Strategy launched in 2008 (Department of Health, 2008). It set out the aim to make good end-of-life care universally available. The key components of the strategy were identifying and talking about dying, patient choice (about where patients wished to live and die), advance care planning, and increasing the rates of home death. Subsequent policy developments built on this first strategy and include the Ambitions for Palliative and End of Life Care: A National Framework for Local Action 2015-2020 (National Palliative and End of Life Care Partnership, 2015) and most recently One Year On: The Government Response to the Review of Choice in End-of-life Care (Department of Health, 2017). Within the policy rhetoric, choice about place of where people are cared for and where they die remain a key focus. In turn, this rhetoric incorporates notions about home being a proxy measure for a 'good death'; dying surrounded by loved ones in a familiar setting. Hospitals are generally considered indicative of poor environments within which to die, both for patients and those close to them 
(Robinson, Gott, \& Ingleton, 2014). More recently however, the notion that home is always the best (and preferred) place of death is being problematised (Pollock, 2015). Furthermore, acute hospitals continue to play a significant role in palliative care provision and hospital admissions towards and at the end-of-life are still high.

In this paper, I take an autoethnographic approach to explore some of the consequences and impact of the disparities in provision of palliative and end-of-life care, which are failing to meet the needs of an ageing population. First, I outline my use of autoethnography, which Chang (2016) suggests is gaining acceptance as a legitimate research method within social and health sciences. Given my autoethnographic approach, I also briefly set out some starting points in terms of my positioning in writing this paper. I then provide a brief account of my father's dying and death, highlighting how this is illustrative of how elderly people reach the end-of-life, following an unpredictable illness trajectory. In doing so, I aim to use this personal account to interrogate the policy landscape that seeks a 'good death' for all. In this sense, outlining an illustrative 'case study' to explore some of the disjunctions between policy perspectives about end-of-life care and the trajectories of dying.

\section{Autoethnography}

Autoethnography is an increasingly recognised and publishable form of research particularly within health sciences (Chang, 2016), although its use is still contested and for some it does not constitute research. Delamont (2009) is a key opponent often cited, arguing that autoethnography is little more than introspective self-obsession with "no analytical mileage" (p. 58) although her arguments are deliberatively provocative to incite debate. Autoethnography differs from ethnography per se, which demands high levels of engagement in the field in order to collect data. In that sense, drawing only on one's own story could appear intellectually lazy and self-indulgent (Letherby, 2015). However, ethnography has a place within intellectual endeavours in that it can rise above self-indulgence through a 
commitment to interrogation of the personal to develop new ways to understand public issues (Brewer, 2005; Ellis, Adams, \& Bochner, 2010;). The key element is to analyse and situate the personal firmly within a sociocultural understanding of the story told. Cook (2014) argues that, if we respect the experiences and stories of our participants, why not our own; to draw upon one's own lived experience "in direct relation to the social context" (p. 271). Indeed, this can take courage to set out one's own story without the benefit of anonymity that we bestow on our research participants.

\section{The Autoethnographer}

The account stems largely from my perspective and so a brief outline of my place in this landscape is necessary. I do not have a nursing or medical background although for 10 years (2006-16) I worked in a School of Health Sciences, within a research centre for the study of supportive, palliative, and end-of-life care. As an academic, I identify primarily as a family sociologist and my interests lie with people and their everyday family lives. Thus, my interest in end-of-life care focuses more on people and those around them living out the endof-life more so than categorising or thinking of people solely as 'patients' and 'carers' and it is this perspective that forms part of my discursive framing. During these 10 years, I acquired considerable knowledge about end-of-life care policy and practice, much of which is situated within nursing and medical literatures that do tend to position people as patients and carers. During my father's weeks in hospital, I found myself on occasion leaving him after visiting and reflecting on communication between my family and me and the healthcare professionals with whom we interacted. In part, these reflections were an intellectual endeavour which provided some distancing from the reality of my father dying. It was a tactic to stop myself crying, wondering if I would see my father alive again. However, I was also writing a paper during this period of time on if, when, and how advance care planning conversations about patients' preferences for place of care (and death) were facilitated and documented (Almack, 
Cox, Moghaddam, Pollock, \& Seymour, 2012). At the same time, in the hospital environment I was/am a lay person; an ordinary member of the public, and I often found myself as bewildered as the rest of my family in terms of seeking information and planning for my father's care with consultants, nurses and other health care professionals.

In writing this paper, I draw from several sources. While my father was dying, I kept a diary and scribbled notes made during telephone conversations with my brother who reported back on meetings with the consultant and charge nurse caring for our father. I also draw on 'supplementary data' (Anderson, 2006), comprising conversations I shared with my mother, sister, daughter, brother, and sister-in-law (which I either recorded or took notes from). I also approached a selected number of trusted academic friends to give me feedback on drafts. Greenhalgh (2017) calls such friends she called upon for her autoethnography, her "interlocutors" (p. 344). In doing so, I was seeking reassurance that the process was a useful and not a narcissistic endeavour (Roth, 2009) that would produce an autoethnography that would be analytically robust in its engagement with "the issues that all should be grappling with in extending a palliative care approach to frail older people" (J. Seymour, personal correspondence, 12 July 2018).

\section{A 'Commonplace' Death}

My father was 89 when he died in September 2011. His death was after a lengthy period of slow decline with several admissions into hospital (planned and unplanned). He spent his final seven and a half weeks in hospital. First, there was an emergency admission by ambulance on a Sunday evening, to a surgical ward in an NHS District General Hospital. He stayed there for about 5-6 weeks until he was moved to a local Community Hospital (now closed), which is where he died. The dying and death of our oldest generations from old age and multiple co-morbidities is something that many families will encounter and probably in increasing numbers in ageing societies. My father's death is reflected in statistics frequently 
quoted about people in developed and developing countries living longer and dying slower (Bone et al., 2017), with the majority of deaths occurring over the age of 65 and mortality rates highest amongst the over 85s (Ruth \& Verne, 2010). Over one third of all deaths are of people aged 85 and over (Office For National Statistics, 2013), but only about 15 per cent of people gaining access to specialist palliative care are in this age group (Public Health England, 2013).

My father was in good health into his 80s. He had laparoscopic surgery for bowel cancer when he was 86 ; cancer cells were found in some lymph nodes but adjuvant chemotherapy was not advised (on the basis that there were no trials on such treatment including people over the age of 70 , so no evidence base as to whether it would prevent the cancer coming back). In any case, my father was adamant he did not want chemotherapy, even if it was an available option. About a year later, he had further surgery (a cystoscopy) for bladder cancer and then cystoscopies were scheduled every six months to check for bladder abnormalities. He felt ill for weeks and experienced such pain after the first cystoscopy that he didn't want further procedures (although consented to one a year later). $\mathrm{He}$ had several episodes of polymyalgia rheumatic, an age-related condition treated with steroids. I observed on visits to my parents that he was becoming less active and he spent more and more time sitting in his armchair. He was also losing weight. Nevertheless, he still went out for a walk each day and he continued with jobs such as cutting the grass and washing the car. He and my mother drove over to my sister's (about an hour's drive) and stayed over every weekend. My sister and her husband owned a village pub and my parents 'helped out'/worked in the pub kitchen producing Sunday lunches, which was a busy service. My sister tried to get my father to do less at the weekends, but he often would not heed her advice to rest, which upset my sister. She and I had a number of conversations about how she worried about him and felt guilty that he was working and not resting. 
At some point, my father's General Practitioner (GP) had informed him that he had some symptoms of heart failure. This information was either not well-explained or my father didn't take in the information given to him. My father would say 'There's nothing wrong with my heart' while acknowledging the GP had indicated there was some degree of heart failure. The very idea of it worried him as five of his six brothers had died from heart attacks. He then began to have fainting fits, diagnosed as relating to low blood pressure, which led to short hospital admissions. These episodes were frightening for my mother who, on a couple of such occasions, thought he was dead.

\section{Identifying 'End-of-life'}

On his $89^{\text {th }}$ birthday, my father remarked that, if he was still around to see in his $90^{\text {th }}$ birthday, he would consider himself a lucky man. After his death, my mother confided that in my father's last year of life, she woke each morning steeling herself to the possibility that my father might have died during the night, such was her sense of his declining health and increasing frailty. Thus, one might imagine that this period of time might fall within a formal definition of end-of-life. However, by whom is the question? It is possible that my father's GP would have been alerted to a need to introduce advance care planning, had he asked himself: 'Would I be surprised if this person were to die in the next 6 - 12 months?'; especially considering my father's age and various health conditions. This 'Surprise Question' is a screening tool that aims to identify people nearing the end of life, albeit used with a wide degree of accuracy, from poor to reasonable (White et al., 2017). However, GPs and district nurses are two key groups who may be well-positioned to recognise patient decline, based on intuition and practice as well as clinical indicators. In England, it has been incorporated into clinical guidelines such as National Institute for Health and Care Excellence for End of Life Care (2011) and adopted into routine clinical practice in various settings, including General Practices. According to policy guidance, the answer 'no' in response to the 
'Surprise Question' could have triggered an initiation of the Gold Standards Framework process, designed to facilitate earlier recognition of people nearing the end of their life and to instigate earlier planning, and better care. Thomas and Gray (2018) highlight, despite significant progress, many patients are still not identified early enough to plan proactive endof-life care.

The dying trajectory from physical and cognitive frailty is highly unpredictable (Cardona-Morrell et al., 2017) and knowing when to implement the end-of-life care pathway can be problematic (Almack et al., 2012; Borgstrom, 2015). The process requires GPs to have the time not only to address immediate problems that might be presented in a consultation but also to have time to reflect on a person's longer term health and gradual decline, which has been described as an "invisible start of the EOLC [end-of-life care] pathway, so gradual it can be missed" (Borgstrom 2013, p. 95). Even when informed by objective clinical indicators, prognostication is inherently difficult. Gold Standards Framework guidance (Thomas, 2011) suggests that prognosis can be over-emphasised at the expense of planning ahead for possible need, especially for those with frailty and co-morbidities. It also suggests that it may be easier to have discussions premised on the basis that 'all is well now but let's look ahead a bit' rather than leaving discussions about preferences and needs (advance care planning) to the point when it needs enacting. In my father's case, I have no idea if this happened and I suspect it did not. Given his history, it appears that there were clinical indicators, but these may become obscured by a patient such as my father who had a determination to continue living, physical but not cognitive frailty, was very proud of still 'working', joking about maybe retiring at 90, and so on. Furthermore, in one conversation I had with my father's GP (during my father's last weeks in hospital), it was suggested that communications from the hospital to the GP practice (discharge notes after his various admissions and surgeries), were inadequate for my father's GP to ascertain a full picture of my father's various ailments. 
At best, the increasing number of hospital admissions and diagnosis of two cancers might have signalled a need for thinking about the needs and care requirements of my father and the support needs of my mother as a 'carer'. However, communication between the hospital and their GP was not always efficient and my parents had no contact with any other healthcare professionals apart from their GP. They were fiercely independent as are many of the oldest generation (http://www.dlf.org.uk/blog/losing-independence-bigger-ageing-worrydying) and had no expectations or desire for additional support; support may have been offered and declined; if it was we (my brother, sister and I) were not informed. Certainly, my parents would not have wanted to ask for additional support or help. Furthermore, despite a policy shift towards patient choice (as a stand in for patient autonomy), my parents were of the generation who still subscribed to the notion characterised by a 'the doctor knows best' mentality.

\section{Being in Hospital: When to Implement Palliative Care?}

My father's final unplanned emergency admission into hospital happened July $27^{\text {th }}$, 2011. We didn't know so at the time, but this was the start of his last weeks of life, first spent on a surgical ward in an NHS district general hospital and later in a local community hospital where he died September $11^{\text {th }} 2011$.

This admission was on a Wednesday afternoon. My mother (also in her 80s) described how my father had started shivering uncontrollably and not knowing what else to do, she called for an ambulance. The paramedics decided to take my father to hospital and my mother followed on in their car. On arrival, already feeling upset and anxious, she couldn't locate where he had been admitted. She phoned my sister in some distress; afraid he might have died in the ambulance. My sister recalls organising staff cover for her pub, jumping in her car to drive to the hospital to support our mother. I lived 100 miles away, my sister about 40 miles away, from the hospital. My brother lived nearest (6 miles from our parents' house, 10 
miles from the hospital) but he wasn't always the first port of call due to his long working hours. My sister owned and ran a pub by herself; six months earlier, her husband had died from a stroke. There was a flurry of phone-calls around the family - we were in any case, all meeting up the following day at my sister's pub. It was her $50^{\text {th }}$ birthday and she wanted to mark the day by burying the ashes of her husband in the local graveyard. We made a plan that my brother would give our mother a lift to the pub and I would drive home with her, stopping off to visit my father in hospital. He was so pleased to see my (and my daughter) but in a dreadful state. He was distressed and embarrassed by bowel incontinence. He soiled the bed and motioned us to leave; my daughter and I moved to behind the curtain round his bed. I went in search of staff while hearing my mother, also distressed, cleaning him and changing his pyjamas.

The main issue initially identified, and the reason for his admission, was inflammation and infection of the gall bladder. This infection was treated by strong antibiotics, but the ward team was unsure if the ongoing symptoms were the result of infection or unfortunate side effects of the antibiotics. A week later, a further course of a new antibiotic was started but we saw little improvement. My father's blood pressure was erratic, and the anaesthetist wasn't confident he would survive an operation.

My brother and his wife, living the closest to the hospital, attended most of the few meetings we had with staff and surgical consultant. My brother had asked if he could take notes during the meetings in order to provide information to his sisters, although the consultant and the charge nurse were hesitant to consent to this. I have the notes that I scribbled down during telephone conversations with my brother, when he reported back from these meetings. We didn't gain much information that helped us make any sense of what was happening. My scribbles indicate reports of investigations including blood tests, which came back normal and a CT scan showed nothing significant; an MRCP revealed abnormalities in 
the liver (I had to look up that this meant 'magnetic resonance cholangiopancreatography'; a special type of magnetic resonance imaging exam that produces detailed images of the hepatobiliary and pancreatic systems, including the liver, gallbladder, bile ducts, pancreas and pancreatic duct). It isn't clear if the latter was followed up (often we weren't even clear on what tests were being carried out and what they were for). Given my father had previously had bowel cancer (Dukes C) and treatment for bladder cancer, we asked if any of his symptoms were cancer-related but this was discounted (although bowel and bladder cancer were noted on his death certificate, along with ischaemic heart disease as secondary causes of death; the primary cause of death was noted as abdominal sepsis). Overall, it was agreed that my father's condition had not changed or improved; there were 'difficult symptoms' and there wasn't a clear plan for the way forward. By this point, he was attached to an IV drip and had a nasal feeding tube. He also had an oxygen mask to use. My mother recalls a traumatic memory of going in to visit one day and finding the oxygen mask on his face but filled with phlegm he had coughed up while drifting in and out of sleep. It seemed apparent he had not been checked on in a while and she wondered how long he had been left in such a mess. It particularly upset her as he was always so meticulous about his appearance.

I discussed my father's condition with clinician colleagues in my workplace. They advised I should broach the suggestion to think about palliative care with ward staff. I contacted the Macmillan Nurse Specialist attached to the hospital's palliative care team, who felt it would be appropriate for her to become involved. However, when I raised this with ward staff, they appeared surprised and questioned why I thought this was necessary and "was I giving up on my father". This is the reverse to the scenario set out by Roscoe and Tullis (2015) where patients and families may wish 'everything' to be done; anything less may be perceived as the staff giving up. It appears there are different perspectives at play in the scenario I outline. On the one hand, hospital staff preoccupied with curative solutions; 
and on the other, a family member who had witnessed an ongoing and now steep decline in her father's health and aware that death was near and trying to prepare for it. It was so frustrating that staff didn't appear to recognise his suffering caused by the ongoing aggressive treatment. My suggestions, including a consultation with the Macmillan Nurse Specialist were discounted. What happened next, which caused great distress for all my father's immediate family members, might have been prevented by a more holistic approach.

One day, about four weeks into my father's stay in hospital, my brother and I had an early morning meeting with the consultant attached to my father's case and the charge nurse. I again broached the topic of whether we were at a stage where palliative care might be the most appropriate way forward, but they said this couldn't really happen because my father didn't acknowledge he was dying.

After this meeting, I went into my father's room (by then he was in a side room). He turned to me and took hold of my hand, saying 'I've had enough, I just want to die'. It was a harrowing experience to see my stoical father in such distress. Active treatment had literally worn him out. Eventually I left my brother with my father and went in search of the charge nurse. I broke down, I remember him being very kind and making me a coffee.

That day all active treatment was withdrawn; staff were then willing to approach the Macmillan hospital team. We were told we could come and go as we wished and didn't have to adhere to visiting hours, we were shown a room we could use, which had kitchen facilities. My father wanted his family round him and we all gathered - my mother, sister, brother and sister-in-law, their two children, my daughter. My father cried, as he realised he might never see the home that he loved again. After a long emotional day, he was prescribed a sleeping tablet and we all left for our various homes (with my daughter and I staying at my parents' house as we often did during those weeks). My father slept well through the night and by morning he was apologetic of the emotions of the previous day and expressed a renewed 
determination to get better. My brother was his first visitor of the day and took him outside in a wheelchair and he had a bacon sandwich, with the bacon all crispy, just as he liked it. He was tearful when my mother, daughter and I visited later, recounting how good that sandwich had tasted, how good to be outside.

His acknowledgment of wanting to die on that one day was enough to get a referral to the palliative care team. Despite my request that I would like to be present when someone came to see my father, the Macmillan Nurse Specialist visited him alone. It was never clear what conversation was held (my father just pointed to a leaflet she had left) and we didn't see anything further of the team. Active treatment resumed without our knowledge. I went in to visit one afternoon and my father was sitting in a chair, feeling distressingly uncomfortable and having a blood transfusion. If this had been discussed with him, he wasn't clear. He was partially deaf and well-practiced at nodding even if he hadn't heard what was being said. Certainly, the blood transfusion had not been discussed with his close family members and I had to seek someone out to ask why it was being done when it had been agreed that my father didn't want any further active treatment.

In all the weeks in the District General Hospital and the time he was in the local Community Hospital, we had some precious times despite all the difficulties and sadness. In his last few weeks, after that day he was in deep distress such that he wanted to die, I often massaged his feet and his neck and shoulders; newly intimate contact that we hadn't shared for many years. We were able to come and go as we pleased; my father regained his stoicism and humour and a determination to get better.

Often my daughter and I sat holding his hands, one of us either side of his bed and doing crosswords with him (I acquired a new patience doing crosswords, which ordinarily I would have refused to engage in). One of the last crosswords we did with him had a clue about gambling odds; he teased us that we should know, being gamblers (we are not; but it 
was a cherished moment to see his humour still intact). Only two days before he died, he said to my mother and sister 'I don't think I'm going to make it out of here (the Community Hospital)'. My mother and sister don't recall how they responded; I often wish I had been there to ask if he was afraid or to follow up on his thoughts at that time.

These experiences outline a case scenario that is not be uncommon in the trajectories of frail elderly people with deteriorating health. Carey et al. (2015) identify the need to improve planning and shared decision-making for hospital patients, particularly where the patient is not responding well to acute medical treatment and there is a risk of dying in the next 1-2 months. Transitions to palliative care approaches are advocated within UK policy guidance; recent models for provision of palliative care advocate a phased transition, with palliative care provided concurrently with active treatment (Department of Health, 2008; National Council for Palliative Care \& National End of Life Care Programme, 2011). However, research exploring transitions to a palliative care approach (from the perspective of healthcare professionals) found this approach was seldom evident in acute hospital settings (Gott, Ingleton, Bennett, \& Gardiner, 2011). One key issue (as evident in my father's case) is that judgments may vary in defining or recognising a patient in need of palliative care (Boyd \& Murray, 2010). Judging prognosis for non-cancer patients is particularly difficult (Shipman et al., 2008) and the dying phase for older people may often only be recognised retrospectively (Seymour \& Gott, 2011). Frail elderly people can present complex clinical situations which may pose difficult dilemmas for healthcare professionals (as well as for patients, and those close to them) in acknowledging and acting on points at which a transition in focus from cure to palliation are required.

Conceptual clarity regarding a palliative approach is vitally necessary in facilitating the integration of such an approach in the ongoing care of people who have chronic lifelimiting conditions (Sawatzky et al., 2016). This integration refers to incorporating hospice, 
palliative, or end-of-life care principles and practices for people with chronic life-limiting conditions within healthcare settings by professionals who do not specialize in palliative care. However, barriers to the introduction of palliative care resonate with my family's experience, including the view that palliative care should only be offered in the final stages of an illness; the complexity of recognising when patients are terminally ill; and healthcare professionals' therapeutic ennui or difficulties in imagining alternative approaches to active treatment (Krisjanson, Toye, \& Dawson, 2003). There are also specific challenges concerning the use of the term palliative care. As noted, in asking the ward team to consider palliative care as an option to introduce as part of my father's care, I was perceived to be "giving up" on my father when what I was aiming for was holistic care. A 'palliative approach', comprising adapting and bringing in palliative care principles to meet the needs of frail older people with declining health, might have avoided the dreadful experience of my father feeling so worn out after several weeks in hospital, that despite his will to live, he just wanted to die (MacArtney, Broom, Kirby, Good, \& Wootton, 2015). While I don’t doubt that good intentions of all the staff involved in my father's care, the harrowing experience of that day when my father said 'I've had enough, I just want to die' lived on in our memories; from my mother's perspective and in her words, "they put him through hell".

\section{Choice and Discussions}

Advance care planning and choice about places of care and death are key factors underpinning end-of-life care policy. These factors are highlighted in policy documents as key to the provision of a good quality experience of dying and death (The Choice in End of Life Care Programme Board, 2015), enabling patient choice and preferences to be discussed, recorded, and acted upon. Studies have emphasised the need for clear communication throughout an illness trajectory, including communication about the purpose of care and treatment, as well as decisions to change the plan of care, including transitions between cure 
and palliation (Meeker, McGinley, \& Jezewski, 2019, Roscoe and Tullis, 2015, Fitzsimons et al., 2007) .

Clearly, these policies and practices did not match the experience for my family or my father throughout his last weeks in hospital. Each of us have memories of those last weeks in hospital (especially the five weeks my father was on the surgical ward at an NHS District General Hospital), characterised by experiences of endless frustration, distress and limited communication. In one conversation with my brother after he'd had a meeting with the ward consultant and charge nurse, he referred to their reluctant agreement that he could take notes, going on to say 'I don't know why, they told me nothing'. He described feeling powerless to get any clear plan of action sorted out. This experience resonates with a discussion by Roscoe and Tullis (2015) who suggest that:

'... patients [and I would add, their family members] do not know what they do not know and their capacity to comprehend medical information and ask pertinent questions may be compromised by a range of factors including emotions, education level and deference to the physician as an authority figure' (2015:77).

This rings true for myself as well as my brother. Somehow, my working-class background creating deference, my social care background left me bewildered in comprehending medical information, notwithstanding my privilege of education to $\mathrm{PhD}$ level and palliative care colleagues advising me. Even smaller things were confusing, such as making sense of different nurse uniforms. For a long time after my father's death, I had strong feelings of guilt and sadness that we hadn't pushed harder to have my Dad moved off that surgical ward earlier. I felt as though by not doing so, that we were somehow complicit in his suffering and that we had failed him. A surgical ward was not the best place for my father, but other options appeared out of reach. 
Potentially, the staff with whom we consulted felt inadequate with regard to communication about end-of-life care and/or genuinely did not know how best to respond to and manage my father's symptoms. This was within the context of a busy acute hospital, with generalist nursing staff facing heavy workloads. Yet, the focus remained on curative care despite evidence that integrating palliative care earlier as part of a phased transition is likely to enhance the experience of care (Gardiner, Ingleton, Gott, \& Ryan, 2015). Finally, the option of moving him was raised. I was not at the meeting where this was discussed by the consultant and charge nurse with my brother and mother. My brother and mother were given the name of the suggested place but little other detail, such that they assumed he was being moved to a care home. It was in fact a Community Hospital, a small unit which offered rehabilitation, symptom control, and palliative and end-of-life care. As far as I know, the question of bringing my father home to die was never really discussed. I was the only one who raised it as an option to consider, in an earlier meeting with my brother and the ward's charge nurse. My mother felt she would be unable to cope, my siblings felt it was not viable, and staff supported these views, saying that it was not a realistic option. Consequently, I did not push to see what kind of support package might have been possible. However, feelings of guilt that we could have done more were hard for me to escape in the early months after he died. I wished, for example, that I had been more assertive in questioning options other than those weeks on the surgical ward; argued further on the question of 'could we get him home' (the home he loved so much).

For many elderly people, the possibility of informed choice does not reflect the reality of their situation; ultimately, my father was not best positioned to fully exercise autonomy or agency. Our family's experience resonated with Borgstrom's (2015) observation that the possibility of control suggested by the concept of choice is not necessarily realised in practice. Given my research area, which included several projects with a focus on advance 
care planning and carrying out an evaluation of the National End of Life Care Programme, I was willing to talk about advance care planning with my parents. They, however, closed down my attempts, which is an interesting reversal of some of our research findings suggesting that older people were more willing to talk and face issues of mortality while their children did not wish to face the prospect of talking about their parents dying (Almack et al., 2012). To facilitate advance care planning requires open discussions about dying and an expectation that individuals will express their preferences. The philosophy of 'choice' has been even more firmly embedded in recent policy documentation (The Choice in End of Life Care Programme Board, 2015) with the pledge that the care people receive at the end of their life "truly offers every individual the chance to live well until they die" (p. 35). This rhetoric is problematic in several ways. While advance care planning is promoted to be undertaken at any age or stage of health, it can be unappealing or difficult to contemplate in light of a prolonged and uncertain trajectory of decline. It also assumes a well-informed consumer and sufficient resources to facilitate choices.

\section{Conclusion}

I have drawn on an account of my father's last weeks of life as an illustrative case study of an increasingly common scenario of dying and death in old age (particularly in resource rich countries such as England), which follows on from a prolonged period of increasing frailty and co-morbidities (Lowrie, Ray, Plummer, \& Yau, 2018). My account resonates with the increasingly common scenario whereby, for elderly people, there is often no clear defining point of recognising dying or of where the end-of-life phase begins; this is a pressing issue within the policy context of end-of-life care in England.

My family's experience of my father spending his last weeks in hospital environments is not uncommon - the oldest age groups are most likely to die in hospital and with the highest hospital death rates being people aged 75 and over (National End of Life Care 
Intelligence Network, 2010). The institutional hospital environment is often considered an inappropriate and undesirable place in which to die yet, despite policy initiatives to increase end-of-life care in the community, many older adults will die in hospital (Brereton et al., 2012). Given this context, we still need hospitals to provide an appropriate environment for older adults requiring end-of-life care (Gardiner \& Barnes, 2011). The existing orthodoxies about choice and preferences, accompanied by the notion that shifting care out of hospitals has to be better for patients and those close to them both fails to take account of nuanced individual and familial experiences and can raise expectations that cannot necessarily be met. Further, these factors obscure the complex and unpredictable realities of dying (Gott, 2014), in particular for what Lowrie et al. (2018) refer to as a 'dying underclass' - those with multiple morbidity and unclear illness trajectories who are frequently not recognised as dying. This population of older people often remain invisible within the current paradigms of palliative and end-of-life care (Pollock \& Seymour, 2018).

Despite good intentions, there are significant disjunctions between the 'blunt' tools of end-of-life care policy discourses and the everyday experiences within families of dying and death of an elderly family member, which, in turn can have distressing and long-lasting impacts for families at and after their family member's end-of-life. All older people are entitled to a good death and there is an urgent need to address the complexities involved in delivering high quality end-of-life care to an elderly population. These complexities and the development of a supportive/palliative approach to caring for frail elderly people could be addressed in a number of ways. These include generic training of all health care professionals in transitions between curative and palliative treatment; good end-of-life communication skills - in particular between healthcare professionals and family members; multidisciplinary work. Finally, as Pollock (2015) identifies, hospitals need to be recognised as places where 
the majority of elderly people still die and as places that can deliver high quality end-of-life care for those dying and their families. 


\section{References}

Almack, K., Cox, K., Moghaddam, N., Pollock, K., \& Seymour, J. (2012). After you: conversations between patients and healthcare professionals in planning for end-oflife care. BMC Palliative Care, 11(1), 1-10. doi:10.1186/1472-684x-11-15

Anderson, L. (2006). Analytic autoethnography. Journal of Contemporary Ethnography, 35(4), 373-395. doi:10.1177/0891241605280449

Bone, A. E., Gomes, B., Etkind, S. N., Verne, J., Murtagh, F. E., Evans, C. J., \& Higginson, I. J. (2018). What is the impact of population ageing on the future provision of end-oflife care? Population-based projections of place of death. Palliative Medicine. 32(2), 329-336. doi:10.1177/0269216317734435

Borgstrom, E. (2013). Planning for death? An ethnographic study of choice and English endof-life care.Unpublished doctorial dissertaion,University of Cambridge.

Borgstrom, E. (2015). Planning for an (un)certain future: Choice within English end-of-life care. Current Sociology, 63(5), 700-713. doi:10.1177/0011392115590084

Boyd, K., \& Murray, S. A. (2010). Recognising and managing key transitions in end-of-life care. BMJ, 341. doi:10.1136/bmj.c4863

Brereton, L., Gardiner, C., Gott, M., Ingleton, C., Barnes, S., \& Carroll, C. (2012). The hospital environment for end-of-life care of older adults and their families: An integrative review. Journal of Advanced Nursing, 68(5), 981-993. doi:10.1111/j.13652648.2011.05900.x

Brewer, J. D. (2005). The public and private in C.Wright Mills's life and work. Sociology, 39(4), 661-677. doi:10.1177/0038038505056026

Cardona-Morrell, M., Lewis, E., Suman, S., Haywood, C., Williams, M., Brousseau, A.-A., Greenway, S. \& Dent, E. (2017). Recognising older frail patients near the end-of-life: 
What next? European Journal of Internal Medicine, 45, 84-90.

doi:10.1016/j.ejim.2017.09.026

Carey, I., Shouls, S., Bristowe, K., Morris, M., Briant, L., Robinson, C., ... \& Hopper, A. (2015). Improving care for patients whose recovery is uncertain. The AMBER care bundle: design and implementation. BMJ Supportive and Palliative Care, 5(1), 12-18. doi:10.1136/bmjspcare-2013-000634

Chang, H. (2016). Autoethnography in health research: Growing pains? Qualitative Health Research, 26(4), 443-451. doi:10.1177/1049732315627432

Cook, P. S. (2014). 'To actually be sociological': Autoethnography as an assessment and learning tool. Journal of Sociology, 50(3), 269-282. doi:10.1177/1440783312451780

Delamont, S. (2009). The only honest thing: autoethnography, reflexivity and small crises in fieldwork. Ethnography and Education, 4(1), 51-63. doi:10.1080/17457820802703507

Department of Health. (2017). One Year On: The Government Response to the Review of Choice in End of Life Care. London: Author.

Department of Health. (2008). End of Life Care Strategy: Promoting high quality care for all adults at the end-of-life. London: Author.

Ellis, C., Adams, T., \& Bochner, A. (2010). Autoethnography: An overview. Forum Qualitative Sozialforschung / Forum: Qualitative Social Research, 12(1). doi: http://dx.doi.org/10.17169/fqs-12.1.1589

Fitzsimons, D., Mullan, D., Wilson, J. S., Conway, B., Corcoran, B., Dempster, M., ... \& Fogarty D. (2007). The challenge of patients' unmet palliative care needs in the final stages of chronic illness. Palliative Medicine, 21(4), 313-322. doi:10.1177/0269216307077711 
Gardiner, C., \& Barnes, S. (2011). Improving environments of care for the end-of-life in hospitals. In M. Gott \& C. Ingleton (Eds.), Living with ageing and dying: Palliative and end of life care for older people (pp. 237-244). Oxford: Oxford University Press.

Gardiner, C., Ingleton, C., Gott, M., \& Ryan, T. (2015). Exploring the transition from curative care to palliative care: A systematic review of the literature. BMJ Supportive and Palliative Care, 5(4), 335-342. doi:10.1136/bmjspcare-2010-000001rep

Gott, M. (2014). Avoidable for whom? Hospital use at the end-of-life. Palliative Medicine, 28(7), 917-918. doi:10.1177/0269216314534807

Gott, M., Ingleton, C., Bennett, M. I., \& Gardiner, C. (2011). Transitions to palliative care in acute hospitals in England: Qualitative study. BMJ, 342. doi:10.1136/bmj.d1773

Greenhalgh, T. (2017). Adjuvant chemotherapy: An autoethnography. Subjectivity, 10(4), 340-357. doi:10.1057/s41286-017-0033-y

Higginson, I. J., Sarmento, V. P., Calanzani, N., Benalia, H., \& Gomes, B. (2013). Dying at home - is it better: A narrative appraisal of the state of the science. Palliative Medicine, 27(10), 918-924. doi:10.1177/0269216313487940

Kristjanson, L., Toye, C., \& Dawson, S. (2003). New dimensions in palliative care: A palliative approach to neurodegenerative diseases and final illness in older people. The Medical Journal of Australia, $179(6$ (Suppl)), 41-43.

Letherby, G. (2015). Bathwater, babies and other losses: A personal and academic story. Mortality, 20(2), 128-144. doi:10.1080/13576275.2014.989494

Lloyd, A., Kendall, M., Carduff, E., Cavers, D., Kimbell, B., \& Murray, S. A. (2016). Why do older people get less palliative care than younger people? European Journal of Palliative Care, 23(3), 132-137. 
Lowrie, D., Ray, R., Plummer, D., \& Yau, M. (2018). Exploring the contemporary stage and scripts for the enactment of dying roles: A narrative review of the literature. Omega: Journal of Death \& Dying, 76(4), 328-350. doi:10.1177/0030222817696541

MacArtney, J. I., Broom, A., Kirby, E., Good, P., \& Wootton, J. (2017). The liminal and the parallax: Living and dying at the end of life. Qualitative Health Research, 27(5), 623633. https://doi.org/10.1177/1049732315618938

Meeker, M.A., McGinley, J.M., Jezewski, M.A. (2019). Metasynthesis: Dying adults' transition process from cure-focused to comfort-focused care. Journal of Advanced Nursing. Early View Online. https://doi.org/10.1111/jan.13970

Murray, S. A., \& Moine, S. (2015). People die everywhere, so care should be optimised in all settings and all along the way. BMJ (Online), 351. doi:10.1136/bmj.h5677

National Council for Palliative Care \& National End of Life Care Programme. (2011). Commissioning End of Life Care. London: Author.

National End of Life Care Intelligence Network. (2010). Variations in Place of Death in England. London: Author. Retrieved from: http://www.endoflifecareintelligence.org.uk/resources/publications/variations_in_place_of_death

National Palliative and End of Life Care Partnership. (2015). Ambitions for Palliative and End of Life Care: A national framework for local action 2015-2020. Retrieved from http://endoflifecareambitions.org.uk/

National Institute for Health and Care Excellence (NICE). End of Life Care for Adults (2011, updated 2017). https://www.nice.org.uk/guidance/qs13. Accessed 25 June 2019.

Office For National Statistics. (2013). Mortality statistics: Deaths registration summary tables. London: Author.

Pollock, K. (2015). Is home always the best and preferred place of death? BMJ, 351. doi:10.1136/bmj.h4855 
Pollock, K., \& Seymour, J. (2018). Reappraising 'the good death' for populations in the age of ageing. Age and Ageing, 47(3), 328-330. doi:10.1093/ageing/afy008

Public Health England. (2013). What we know now: New information collated by the National End of Life Care Intelligence Network. London: Author.

Robinson, J., Gott, M., \& Ingleton, C. (2014). Patient and family experiences of palliative care in hospital: What do we know? An integrative review. Palliative Medicine, 28(1), 18-33. doi:10.1177/0269216313487568

Roscoe, L.A. \& Tullis, J A. (2015). The meaning of everything: communication at the end of life. Journal of Medicine and the Person, 13 (2), 75-81.

Roth, W-M. (2009) Auto/ethnography and the question of ethics. Forum Qualiative Sozialforschung/Forum: Qualiative Social Research, 10(1), Art. 38.

Ruth, K., \& Verne, J. (2010). Deaths in Older Adults in England. London: National End of Life Care Intelligence Network. Retrieved from: http://www.endoflifecareintelligence.org.uk/resources/publications/deaths_in_older_adults

Sawatzky, R., Porterfield, P., Lee, J., Dixon, D., Lounsbury, K., Pesut, B., Roberts, D., Taylor, C., Voth, J., \& Stajduhar, K. (2016). Conceptual foundations of a palliative approach: A knowledge synthesis. BMC Palliative Care, 15(5). doi:10.1186/s12904016-0076-9

Seymour, J., \& Gott, M. (2011). The challenges of health technology for ageing and dying. In M. Gott \& C. Ingleton (Eds.), Living with ageing and dying: Palliative and end-of-life care for older people (pp. 42-51). Oxford: Oxford University Press.

Shipman, C., Gysels, M., White, P., Worth, A., Murray, S.A., Barclay, S., Forrest, S., Shepherd, J., Dale, J., Dewar, S., Peters, M., White, S., Richardson, A., Lorenz, K., Koffman, J. \& Higginson, I.J. (2008). Improving generalist end of life care: national 
consultation with practitioners, commissioners, academics, and service user groups. BMJ, 337 (7674). doi: 10.1136/bmj.a1720 doi:10.1136/bmj.a1720

The Choice in End of Life Care Programme Board. (2015). What's Important to Me: A review of chioce in end-of-life care. London: Author.

Thomas, K. (2011). The GSF Prognostic Indicator Guidance (4th ed.). Retrieved from: https://www.goldstandardsframework.org.uk/cdcontent/uploads/files/General\%20Files/Prognostic\%20Indicator\%20Guidance\%20Oct ober\%202011.pdf

Thomas, K., \& Gray, S. M. (2018). Population-based, person-centred end-of-life care: time for a rethink. British Journal of General Practice, 68(668), 116-117. doi:10.3399/bjgp18X694925

White, N., Kupeli, N., Vickerstaff, V. \& Stone, P. (2017). How accurate is the 'Surprise Question' at identifying patients at the end of life? A systematic review and metaanalysis. BMC Medicine, 15, 139. https://doi.org/10.1186/s12916-017-0907-4 